\title{
FUNDAMENTO CONSTITUCIONAL-POLÍTICO PARA O CONTROLE EXTERNO
}

\author{
Jair Teixeira dos Reis ${ }^{1}$
}

Audren Marlei Anzolin²

\section{Resumo}

Este artigo tem como objetivo destacar o papel desempenhado pelas Cortes de Contas no estado brasileiro a partir da Carta de 1988, na atribuição de exercer o controle externo e a fiscalização contábil, financeira, orçamentária, operacional e patrimonial; apontar irregularidades e propor métodos adequados de aplicação da receita pública. Mereceu, também, análise o controle interno exercido pelo Ministério da Transparência e Controladoria-Geral da União, o controle social, o controle parlamentar e o controle judicial ou judiciário. Optou-se por um estudo que teve como base uma estratégia qualitativa de pesquisa. Orientada numa pesquisa bibliográfica, consignada em obras contemporâneas, em sua grande maioria, de autores nacionais. Além, de uma análise da legislação vigente, considerando o contexto histórico, que representa alguns dos marcos normativos do controle da administração pública no Brasil.

Palavras-chave: Controle Interno. Controle Externo. Controle Social. Controle Administrativo.

\section{INTRODUÇÃO}

Segundo Pessanha $(2017)^{3}$, a ineficácia e a inexperiência do Legislativo na fiscalização dos gastos públicos justificaram a criação de órgãos específicos - conhecidos

\footnotetext{
${ }^{1}$ Jurista, Professor Universitário e Auditor Fiscal do Trabalho. Professor do Mestrado Profissional em Gestão PúblicaDoutorando em Direito Econômico e de Empresa pela Universidad Internacional Iberoamericana - UNINI México (UNINI-MX). Universidade Federal do Espírito Santo - UFES - Brasil. ORCID iD: https://orcid.org/0000-0002-6706-9307 Lattes: http://lattes.cnpq.br/2871270093927513 Email: jairteixeirareis@gmail.com

${ }^{2}$ Graduação em Direito pela Pontifícia Universidade Católica do Paraná. Especialização em Direito Contemporâneo pelo Instituto Brasileiro de Estudos Jurídicos. Mestrado em Ciência Política pela UFPR. Atualmente é docente do Centro Universitário Internacional - Uninter. Brasil. ORCID iD: Lattes: E-mail: AUDREN.A@uninter.com

${ }^{3}$ PESSANHA, Charles. O tribunal de contas, o Congresso Nacional e as Contas Presidenciais. Disponível em

http://www.congresoalacip2017.org/arquivo/downloadpublic2?q=YToyOntzOjY6InBhcmFtcyl7czozNTo iYToxOntzOjEwOiJJRF9BUlFVSVZPIjtzOjQ6IjI5NjUiO30iO3M6MToiaCI7czozMjoiMTk1MzNhNTB 1YWM0MDZjZGJiNjk3ZTJjYTY0MmY3Y2UiO30\%3D, Acessado em 16 de Out. 2018.
} 
como instituições superiores de controle - para, direta ou indiretamente, colaborar com o Legislativo no controle externo da administração pública.

Etimologicamente, o vocábulo "controle" encontra muitas definições, a exemplo da que se lê nos Dicionários, como "vigilância e verificação administrativa. Fiscalização financeira. Ato ou poder de dominar, regular, guiar ou restringir" ${ }^{4}$ ou "fiscalização exercida sobre as atividades de pessoas, órgãos, departamentos, ou sobre produtos, etc., para que tais atividades, ou produtos, não se desviem das normas preestabelecidas"5.

Por controle devem ser entendidos os atos de fiscalização e correção e as medidas repressivas que possam levar à extinção ou regularização dos atos praticados pela Administração Pública ${ }^{6}$, incluindo os da Administração Indireta.

Conforme Rocha ${ }^{7}$, atuando sobre os próprios órgãos estatais, o controle desempenha importante papel nas relações entre Estado e sociedade, contribuindo para a garantia do regime democrático. À medida que uma sociedade se organiza, surgem necessidades que devem ser preenchidas sem que os direitos e liberdades individuais sejam comprometidos.

Assim, o Estado relaciona-se permanentemente com a sociedade. Dessas relações surgem as funções que lhe são próprias, exercidas por meio dos seus órgãos - instituições burocráticas que prestam serviços públicos, ligados a uma das funções fundamentais: executiva, legislativa ou jurídica. O conjunto de órgãos constitui, formalmente, a Administração Pública.

Ensina-nos, ainda, Rocha $^{8}$, que o Estado se submete, então, à ordem e à eficiência administrativas, e à eficácia dos seus atos. Esses princípios criam mecanismos ou sistemas de controle das atividades estatais, defendendo tanto a própria Administração Pública, como os direitos e garantias coletivos.

Existem várias modalidades de controle, dentre eles, destacamos o Controle Administrativo, o Parlamentar e o Judicial ou Judiciário.

O Controle Administrativo reflete na modalidade de controle exercida pela própria Administração Pública, no âmbito de cada Poder. Neste sentido, os poderes Legislativo, Executivo e Judiciário, quando no exercício da função administrativa do estado, deverão

\footnotetext{
${ }^{4}$ AUlete, Caldas. Dicionário Contemporâneo da Língua Portuguesa, Rio de Janeiro, Editora Delta, $3^{\mathrm{a}}$ Edição Brasileira, Volume II, 1978.

${ }^{5}$ FERREIRA, Aurélio Buarque de Holanda. Novo Dicionário da Língua Portuguesa. Rio de Janeiro, Editora Nova Fronteira, $2^{\mathrm{a}}$ edição revista e aumentada, 1986.

6 Todos os Poderes, quando desempenham a função administrativa, suportam as modalidades de controle incidentes sobre esta forma de atuação do Estado.

${ }^{7}$ ROCHA, C. Alexandre Amorim. O Modelo de Controle Externo Exercido pelos Tribunais de Contas e as Proposições Legislativas sobre o Tema. Disponível em: $<$ http://www.planalto.gov.br/CCIVIL/Consulta_Publica/agencia_nacion.htm>. Acessado em: 04 jun.2018. ${ }^{8}$ Ibidem.
} 
desenvolver um sistema de controle sobre suas atividades. O Controle Administrativo é espécie de controle interno, pois não há, em seu exercício, interferência de um poder sobre o outro. Este controle busca enfrentar questões relacionadas ao mérito ${ }^{9}$ (oportunidade e conveniência) e à legalidade dos atos da Administração.

Para Jardim ${ }^{10}$, os sistemas de controle são dois: o interno e o externo. O primeiro tem lugar no interior dos três Poderes e nas demais entidades atreladas ao orçamento público, enquanto o segundo se opera no Parlamento com o suporte técnico dos Tribunais de Contas.

Ambos consistem na fiscalização contábil, financeira, orçamentária, operacional e patrimonial das pessoas constitucionais, bem como das entidades da Administração direta e indireta, observando-se que essa auditoria se realiza no interior de cada Poder.

Assim, são dois os sistemas de controle definidos pela Constituição Federal: a) o controle interno, realizado pelos próprios órgãos do aparelho estatal, e b) o controle externo, realizado pelo Poder Legislativo, que conta com o auxílio dos tribunais ou cortes de contas.

A pesquisa focou o estudo do controle externo sob o aspecto constitucional jurídico, o que foi demonstrado a partir da verificação detalhada de sua definição, estruturas, e especificamente das demais modalidades de controle existente no ordenamento jurídico brasileiro.

Descreveu o papel desempenhado pelas Cortes de Contas no estado brasileiro, como objetivo geral, a partir da novel Carta de 1988, na atribuição de exercer o controle externo e a fiscalização contábil, financeira, orçamentária, operacional e patrimonial. Apresentou, como objetivos específicos, a identificação dos modelos de controle; a definição dos sistemas de controles prescritos na Constituição Federal; analisou a amplitude dos sistemas de controle e definiu o controle social ou popular.

\section{CONTROLE NO ESTADO BRASILEIRO}

A democracia consubstanciada na teoria de tripartição dos poderes necessita da participação para se efetivar sob o aspecto material, uma vez que o próprio princípio democrático

\footnotetext{
${ }^{9}$ A Administração Pública pode reavaliar critérios de conveniência e oportunidade, modificando seus atos e contratos ou promovendo sua extinção de forma unilateral, por meio da Revogação e da rescisão. O controle de mérito vai incidir sobre atos e contratos válidos, pois foram praticados ou celebrados de acordo com a lei, mas que recomendam uma nova avaliação dos critérios de conveniência e oportunidade que justificaram a sua decisão.

O controle de mérito realizado pela Administração Pública acarreta a extinção do ato administrativo pela revogação, e do contrato administrativo, pela rescisão.

${ }^{10}$ JARDIM, Eduardo Marcial Ferreira. Manual de Direito Financeiro e Tributário. 8. ed. São Paulo: Saraiva, 2007.
} 
implica participação nos processos de decisão, sejam eles constituídos a partir dos órgãos estatais de controle, tais como o Ministério Público e os Tribunais e Controles de Contas, pois não há como se negar que a democracia desloca o poder para o povo, sendo que o cidadão tem o direito de participar ativamente das decisões acerca das políticas públicas, sob pena de estar-se difundindo uma democracia meramente retórica. Neste artigo mereceu destaque o controle social ou popular, onde se permite ao cidadão denunciar irregularidades ou ilegalidades perante as cortes de contas.

Conforme lição de Marin \& Bertarello (2012) "11 "na democracia, os cidadãos, embora coletivamente soberanos, também são, como indivíduos, participantes das contendas que julgam coletivamente. A equidade entre os cidadãos exige que participem como iguais". Democracia sem participação do cidadão no processo de tomada de decisões públicas não é democracia; assim, já mencionava Aristóteles que "aquele que tem o poder de tomar parte na administração deliberativa ou judicial de alguma cidade, dizemos que é cidadão daquela cidade" (Aristóteles, 2010, p. 115), ou, pode-se dizer, o exercício democrático da cidadania perpassa pela participação ativa do cidadão no espaço público.

\subsection{CONTROLE INTERNO}

Pode-se definir Controle Interno como - todo aquele realizado pela entidade ou órgão responsável pela atividade controlada, no âmbito da própria Administração. Assim, qualquer controle efetivado pelo Executivo sobre seus serviços ou agentes é considerado interno, como interno será também o controle do Legislativo ou do Judiciário, por seus órgãos de administração, sobre seu pessoal e os atos administrativos que pratique ${ }^{12}$.

O controle interno encontra fundamento no art. 74 da CRFB, o qual determina que os Poderes Executivo, Legislativo e Judiciário devem manter, de forma integrada, sistema de controle interno com a finalidade de:

a) avaliar o cumprimento de metas do plano plurianual e a execução dos orçamentos públicos;

b) comprovar a legalidade e avaliar os resultados, sob os aspectos de eficiência e eficácia, da gestão orçamentária, financeira e patrimonial dos órgãos e entidades da administração;

c) exercer o controle das operações de crédito;

d) apoiar o controle externo.

${ }^{11}$ MARIN, Jeferson Dytz; BERTARELLO, Marina. Democracia e políticas públicas: uma leitura a partir dos direitos humanos. Revista de Estudos Constitucionais, Hermenêutica e Teoria do Direito (RECHTD) 4(1): 57-64 janeiro-junho 2012.

${ }^{12}$ MEIRELLES, Hely Lopes. Direito Administrativo Brasileiro. 22. ed. São Paulo: Malheiros, 1997. 
O Controle Interno será prévio, concomitante e subsequente ou posterior, em relação à legalidade dos atos praticados. Dependendo da situação, poderá a legislação estabelecer sobre quais atos será realizado controle prévio. O controle concomitante ocorre durante a realização da despesa e o subsequente ou a posteriori permite saber, exatamente, a que se destinou a despesa e seu respectivo fundamento legal, conforme arts. 76 a 80, da Lei $n^{\circ} 4.320 / 64$ :

Art. 76. O Poder Executivo exercerá os três tipos de controle a que se refere o artigo 75, sem prejuízo das atribuições do Tribunal de Contas ou órgão equivalente.

Art. 77. A verificação da legalidade dos atos de execução orçamentária será prévia, concomitante e subsequente.

Art. 78. Além da prestação ou tomada de contas anual, quando instituída em lei, ou por fim de gestão, poderá haver, a qualquer tempo, levantamento, prestação ou tomada de contas de todos os responsáveis por bens ou valores públicos.

Art. 79. Ao órgão incumbido da elaboração da proposta orçamentária ou a outro indicado na legislação, caberá o controle estabelecido no inciso III do artigo 75 .

Parágrafo único. Esse controle far-se-á, quando for o caso, em termos de unidades de medida, previamente estabelecidos para cada atividade.

Art. 80. Compete aos serviços de contabilidade ou órgãos equivalentes verificar a exata observância dos limites das cotas trimestrais atribuídas a cada unidade orçamentária, dentro do sistema que for instituído para esse fim.

No Brasil, prevaleceu, até recentemente, o sistema centralizado vinculado ao Ministério da Fazenda. Os Decretos da Presidência da República ${ }^{0} 4.113$, de 5 de fevereiro de 2002, e $4.177^{13}$, de 28 de março de $2002^{14}$, porém, alteraram este quadro profundamente: o primeiro decreto transferiu a Secretaria Federal de Controle Interno (SFC) para a estrutura da Casa Civil da Presidência da República; o último, para a Corregedoria-Geral da União ${ }^{15}$.

Conforme art. 66 da Lei n 13.502/2017, constituem área de competência do Ministério da Transparência e Controladoria-Geral da União:

I - providências necessárias à defesa do patrimônio público, ao controle interno, à auditoria pública, à correição, à prevenção e ao combate à corrupção, às atividades de ouvidoria e ao incremento da transparência da gestão no âmbito da administração pública federal;

II - decisão preliminar acerca de representações ou denúncias fundamentadas que receber, com indicação das providências cabíveis;

\footnotetext{
${ }^{13}$ Art. 1ำ Ficam transferidas da estrutura do Ministério da Fazenda para a da Casa Civil da Presidência da República a Secretaria Federal de Controle Interno, órgão central do Sistema de Controle Interno do Poder Executivo Federal, e a Comissão de Coordenação de Controle Interno.

${ }^{14}$ Art. 1ํ Ficam transferidas da estrutura da Casa Civil da Presidência da República para a da CorregedoriaGeral da União a Secretaria Federal de Controle Interno e a Comissão de Coordenação de Controle Interno. Art. $8^{\circ}$ Revoga-se o Decreto $n^{\circ} 4.113$, de 5 de fevereiro de 2002, e o inciso II do art. $2^{\circ}$ do Decreto $n^{\circ} 4.118$, de 7 de fevereiro de 2002.

${ }^{15}$ A Lei $n^{\circ} 13.341$, de 29 de setembro de 2016, em seu art. Art. $3^{\circ}$ cria:

I - o Ministério da Transparência, Fiscalização e Controladoria-Geral da União - CGU; e
} 
III - instauração de procedimentos e processos administrativos a seu cargo, constituindo comissões, e requisição de instauração daqueles injustificadamente retardados pela autoridade responsável;

IV - acompanhamento de procedimentos e processos administrativos em curso em órgãos ou entidades da administração pública federal;

$\mathrm{V}$ - realização de inspeções e avocação de procedimentos e processos em curso na administração pública federal, para exame de sua regularidade, e proposição de providências ou a correção de falhas;

VI - efetivação ou promoção da declaração da nulidade de procedimento ou processo administrativo e, se for o caso, da apuração imediata e regular dos fatos envolvidos nos autos e na nulidade declarada;

VII - requisição de dados, informações e documentos relativos a procedimentos e processos administrativos já arquivados por autoridade da administração pública federal;

VIII - requisição a órgão ou entidade da administração pública federal de informações e documentos necessários a seus trabalhos ou atividades;

IX - requisição a órgãos ou entidades da administração pública federal de servidores ou empregados necessários à constituição de comissões, incluídas as que são objeto do disposto no inciso III deste artigo, e de qualquer servidor ou empregado indispensável à instrução de processo ou procedimento;

$X$ - proposição de medidas legislativas ou administrativas e sugestão de ações necessárias a evitar a repetição de irregularidades constatadas;

XI - recebimento de reclamações relativas à prestação de serviços públicos em geral e à apuração do exercício negligente de cargo, emprego ou função na administração pública federal, quando não houver disposição legal que atribua competências específicas a outros órgãos; e

XII - execução das atividades de controladoria no âmbito do Poder Executivo federal.

A implementação da transparência permitiu à sociedade um acompanhamento mais efetivo da utilização dos recursos públicos por parte dos gestores da administração direta e indireta.

\subsection{CONTROLE EXTERNO}

O controle externo, por sua vez, é "por excelência, um controle político de legalidade ${ }^{16}$ contábil e financeira" 17 , destinando-se a comprovar: a) a probidade dos atos da administração; b) a regularidade dos gastos públicos e do emprego de bens, valores e dinheiros públicos; c) a fiel execução do orçamento. O Poder Legislativo exercita esse controle diretamente, por meio de atos que lhe são constitucionalmente atribuídos (p. ex., a autorização para a obtenção de empréstimos, a realização de operações de crédito externo por estados e municípios e a sustação de contratos administrativos), ou indiretamente, por meio das cortes de contas (i.e., órgãos incumbidos de auxiliar o Legislativo no exercício da fiscalização financeira e orçamentária).

\footnotetext{
${ }^{16}$ No Controle de Legalidade será verificada a compatibilidade da atuação da Administração Pública com a Lei. Visto que a legalidade é princípio expresso na Carta Constitucional, vinculando toda a atividade administrativa do Estado.

${ }^{17}$ MEIRELLES, Hely Lopes. Direito Administrativo Brasileiro. 22. ed. São Paulo: Malheiros, 1997.
} 
Ainda, conforme Meirelles ${ }^{18}$, Controle Externo, é o que se realiza por órgão estranho à Administração responsável pelo ato controlado, como, por exemplo, a apreciação das contas do Executivo e do Judiciário pelo Legislativo; a auditoria do Tribunal de Contas sobre a efetivação de determinada despesa do Executivo; a anulação de um ato do Executivo por decisão do Judiciário; a sustação de ato normativo do executivo pelo Legislativo (CF, art. 49, V).

De acordo com os artigos 81 e 82 da Lei n ${ }^{\circ} 4.320 / 64$, o Controle Externo se processa:

\begin{abstract}
Art. 81. O controle da execução orçamentária, pelo Poder Legislativo, terá por objetivo verificar a probidade da administração, a guarda e legal emprego dos dinheiros públicos e o cumprimento da Lei de Orçamento.

Art. 82. O Poder Executivo, anualmente, prestará contas ao Poder Legislativo, no prazo estabelecido nas Constituições ou nas Leis Orgânicas dos Municípios.

$\S 1^{\circ}$ As contas do Poder Executivo serão submetidas ao Poder Legislativo, com Parecer prévio do Tribunal de Contas ou órgão equivalente.

$\S 2^{\circ}$ Quando, no Município não houver Tribunal de Contas ou órgão equivalente, a Câmara de Vereadores poderá designar peritos contadores para verificarem as contas do prefeito e sobre elas emitirem parecer.
\end{abstract}

Em síntese, o Controle Interno é aquele exercido dentro de um mesmo Poder, automaticamente ou por meio de órgãos integrantes de sua própria estrutura.

O Controle Interno é um controle pleno, de legalidade, conveniência, oportunidade e eficiência conforme Súmula $n^{\circ} 473$ do STF:

A administração pode anular seus próprios atos, quando eivados de vícios que os tornam ilegais, porque deles não se originam direitos; ou revogá-los, por motivo de conveniência ou oportunidade, respeitados os direitos adquiridos, $e$ ressalvada, em todos os casos, a apreciação judicial ${ }^{19}$.

Por outro lado, diz Controle Externo aquele exercido por um Poder sobre os atos e contratos administrativos praticados por outro Poder.

O Controle Externo visa comprovar a probidade da Administração e a regularização do emprego dos bens e dinheiros públicos, sendo um controle político de legalidade contábil e financeira.

São exemplos de situações de Controle Externo: a) a sustação, pelo Congresso Nacional, de atos normativos do Poder Executivo que exorbitem do poder regulamentar (CF, art. 49, V); b) a anulação de um ato do Poder Executivo por decisão judicial; c) o julgamento anual pelo Congresso Nacional, das contas prestadas pelo Presidente da República e a apreciação dos relatórios, por ele apresentados, sobre a execução dos planos de governo (CF, art. 49, IX); e d) a

\footnotetext{
${ }^{18}$ MEIRELLES, Hely Lopes. Direito Administrativo Brasileiro. 22. ed. São Paulo: Malheiros, 1997.

${ }^{19}$ Art. 80 da Constituição do Estado do Rio de Janeiro - A administração pública tem o dever de anular os próprios atos, quando eivados de vícios que os tornem ilegais, bem como a faculdade de revogá-los, por motivo de conveniência ou oportunidade, respeitados neste caso os direitos adquiridos, além de observado, em qualquer circunstância, o devido processo legal.
} 
auditoria realizada pelo Tribunal de Contas sobre as despesas realizadas pelo Poder Executivo em nível, Federal, Estadual, Distrital e Municipal.

\subsection{MODALIDADES DE CONTROLE}

Para Pessanha $(2018)^{20}$, o processo de redemocratização brasileiro e a criação de instituições de controle modernas e independentes pelo constituinte de 1988, dotaram as instituições responsáveis pelo controle externo do que há de mais moderno e eficaz em termos de fiscalização financeira e orçamentária, equipando-as não apenas para uma verificação de procedimentos, mas também para a avaliação qualitativa dos resultados, mediante os princípios da economicidade e legitimidade.

Podemos inferir as seguintes modalidades de Controle em âmbito geral: a) Controle da Legalidade: Verifica a conformidade do ato com a lei; b) Controle de Mérito: Avalia a conveniência e oportunidade do ato praticado; c) Controle de Gestão: Avalia o desempenho da Administração.

Já em função do Poder, órgão ou autoridade que o exercita, o controle pode ser: a) Administrativo (interna corporis); b) Parlamentar (externa corporis); c) Judicial (corolário do monopólio à Jurisdição).

Consoante ensinamentos de Oliveira ${ }^{21}$, considera-se como controle parlamentar aquele exercido por órgãos do Poder Legislativo, incidindo sobre a atividade administrativa desenvolvida por outro poder. A Constituição atribui esse poder a função de controle e fiscalização sobre toda a atividade que envolver a aplicação de recursos públicos. Nesse sentido, vale a pena destacar a atuação dos Tribunais de Contas na sua atividade de auxílio do Poder Legislativo.

Neste diapasão, o Controle Parlamentar é exercido pelos órgãos legislativos ou por comissões parlamentares sobre os atos do Poder Executivo, dividindo-se em dois grandes ramos: Político - visando à garantia dos interesses superiores do Estado e da comunidade; Técnico voltado essencialmente para a fisscalização financeira, orçamentária, contábil, operacional e patrimonial.

\footnotetext{
${ }^{20}$ PESSANHA, Charles. O tribunal de contas, o Congresso Nacional e as Contas Presidenciais. Disponível em

http://www.congresoalacip2017.org/arquivo/downloadpublic2?q=YToyOntzOjY6InBhemFtcyI7czozNTo iYToxOntzOjEwOiJJRF9BUIFVSVZPIjtzOjQ6Ij15NjUiO30iO3M6MToiaCI7czozMjoiMTk1MzNhNTB IYWM0MDZjZGJiNjk3ZTJjYTY0MmY3Y2UiO30\%3D, Acessado em 16 de Out. 2018.

${ }^{21}$ OLIVEIRA, Cláudio Brandão de. Manual de Direito Administrativo. 3. ed. Rio de Janeiro: Impetus, 2006.
} 
Enquanto o Controle Político é realizado pelo Poder Legislativo com exclusividade, o Controle Técnico é exercido com auxílio do Tribunal de Contas.

A fiscalização financeira diz respeito ao ingresso e à saída de dinheiro. A Orçamentária incide sobre a correta aplicação da lei orçamentária, ou seja, as verbas apenas podem ter a destinação prevista no texto da lei especial devidamente aprovada. A fiscalização Contábil, por intermédio da contabilidade, em verdade é técnica que instrumentaliza o controle. Assim, a contabilidade financeira tem por objeto registrar sistematicamente as transações a que dá lugar a execução do orçamento. A Patrimonial significa e diz respeito à própria execução do orçamento, pois, o patrimônio compõe-se dos bens pertencentes ao Estado, sejam eles de cunho econômico ou não. As alterações patrimoniais devem ser fiscalizadas pelas autoridades públicas em benefício da preservação dos bens que integram o patrimônio público. A referência à fiscalização Operacional diz respeito à obediência aos meios legais de liberação de verbas ou de sua arrecadação. A operacionalidade significa que deve haver rigoroso controle sobre as formas de procedimento da despesa, atendendo-se ao atingimento dos objetivos traçados ${ }^{22}$.

O Controle Judicial efetuado pelo Poder Judiciário exerce o controle da legalidade e da constitucionalidade dos atos praticados pelos demais poderes. Outrossim, na hipótese de provocação de eventual interessado, deve o Magistrado manifestar-se sobre a legalidade dos atos da Administração Pública, verificando a sua compatibilidade com a lei e demais atos normativos, pois a Constituição Federal de 1988 atribui ao Poder Judiciário a função de decidir conflitos de interesse, definindo como a lei será aplicada em um determinado caso concreto.

O Poder Judiciário analisa a legalidade dos atos da Administração Pública, não sendo possível o controle judicial do mérito da atividade administrativa do Estado. Entenda-se por mérito o uso correto da discricionariedade administrativa (conveniência e oportunidade).

O art. 74, §, $2^{\circ}$ da Lei Maior de 1988 prescreve a existência do Controle Social nos seguintes termos:

Art.74 - Os Poderes Legislativo, Executivo e Judiciário manterão, de forma integrada, sistema de controle interno com a finalidade de:(...)

$\S 2^{\circ}$ - Qualquer cidadão, partido político, associação ou sindicato é parte legítima para, na forma da lei, denunciar irregularidades ou ilegalidades perante o Tribunal de Contas da União.

Assim, o Controle Social mereceu do legislador constituinte uma importância salutar que poderá ser ampliada pelos demais sistemas de controles vigentes.

\footnotetext{
${ }^{22}$ OLIVEIRA, Regis Fernandes de. HORVATH, Estevão. Manual de Direito Financeiro. 6. ed. São Paulo: Editora Revista dos Tribunais, 2003.
} 


\subsection{AMPLITUDE DOS SISTEMAS DE CONTROLE}

Inicialmente, é salutar entender, sob o ponto de vista da Ciência Política, o surgimento dos sistemas de controle.

Leciona, com muita profundidade, Pessanha $(2018)^{23}$, ao discorrer que a ineficácia e a inexperiência do Legislativo na fiscalização dos gastos públicos justificaram a criação de órgãos específicos - conhecidos como instituições superiores de controle - para, direta ou indiretamente, colaborar com o Legislativo no controle externo da administração pública.

Fica patente que, nas palavras de Pessanha (2017) o tribunal de contas é uma instituição característica da democracia continental europeia. Sua organização obedece a uma variedade de modelos. São órgãos de natureza colegial, geralmente independentes, ou de relativa autonomia, em relação ao governo e à administração pública.

A análise dos arts. 70 e 71 da Carta Constitucional revela ter havido um profundo alargamento do controle efetuado pelos Tribunais de Contas. Tradicionalmente, limitava-se a ser um controle de Legalidade, é dizer, aferia-se a conformidade do ato praticado com o disposto na lei. Podia ser chamado mesmo de um controle jurídico formal, que não levava em conta outros aspectos do ato controlado senão o da sua adequação ao disposto na lei. Esta modalidade fiscalizatória não deixou de existir. Acontece, entretanto, que há, ao lado dela, um controle de Legitimidade ${ }^{24}$ e de Economicidade.

Todos os governos sempre se apresentaram como legítimos por se instituírem como aptos pela promoção do bem comum. No entanto, o conceito de legitimidade passou a merecer maior atenção ou referência no processo de (re)democratização dos países. Passou-se a associar legitimidade com democracia por espelhar a participação popular na escolha dos governantes.

\begin{tabular}{|c|c|c|}
\hline Fenômeno & Dimensão & Características \\
\hline Legalidade & Jurídica & Conformidade com a(s) lei(s) \\
\hline Legitimidade & Ideológica & $\begin{array}{c}\text { Legalidade + Conformidade com } \\
\text { valores, padrões e ideologia. }\end{array}$ \\
\hline
\end{tabular}

Fonte: CASTRO, 2004.

${ }^{23}$ PESSANHA, Charles. Controle Externo: a função esquecida do legislativo no Brasil. Disponível em http://www.schwartzman.org.br/simon/fest12_charles.pdf, acessado em: 14 out. 2018.

${ }^{24}$ A Legitimidade está relacionada com o respeito ao interesse público, à impessoalidade e à moralidade. 
A expressão Legitimidade conforme demonstrado na tabela acima, é bem mais ampla que a mera legalidade. É ilegal o ato que afronta o disposto na lei. A Legitimidade vai além. Um ato pode ser legal, mas não ser legítimo por estar em descompasso com os valores fundamentais da coletividade. Destarte, um dispêndio excessivo com atividades de representação ou mesmo com cerimônias festivas, embora regulares do ponto de vista legal, visto que financiados por verbas competentes do orçamento, podem ter a sua Legitimidade questionada. É dizer, reconhecer-se que aquela despesa transcende ao que seria razoável a um ato daquela natureza. É sem dúvida nenhuma uma grande porta que se abre ao controle externo e que poderá por um cobro aos dispêndios excessivos com certos gastos suntuosos que debaixo da ordem anterior não encontravam instrumentos adequados de reparação. Não menos importante, ainda, afigura-se o controle exercido quanto à Economicidade do ato ${ }^{25}$.

O controle da Legitimidade aperfeiçoa o controle da Legalidade, representando um plus em relação a este. Significa afirmar que o controle externo não se restringe ao confronto formal entre o ato e a lei, mas também deve observar se o ato, em sua substância, se ajusta à lei e aos demais princípios que regem uma boa administração ${ }^{26}$.

Outra relação que é comumente feita é a da legitimidade com o poder. Legitimidade é uma qualidade do poder, enquanto legalidade se refere ao seu exercício. Bobbio (1998, p. 674) ${ }^{27}$ ensina:

\begin{abstract}
Na linguagem política, entende-se por legalidade um atributo e um requisito do poder, daí dizer-se que um poder é legal ou age legalmente ou tem o timbre da legalidade quando é exercido no âmbito ou de conformidade com leis estabelecidas ou pelo menos aceitas. Embora nem sempre se faça distinção, no uso comum e muitas vezes até no uso técnico, entre legalidade e legitimidade, costuma-se falar em legalidade quando se trata do exercício do poder e em legitimidade quando se trata de sua qualidade legal: o poder legítimo é um poder cuja titulação se encontra alicerçada juridicamente; o poder legal é um poder que está sendo exercido de conformidade com as leis. O contrário de um poder legítimo é um poder de fato; o contrário de um poder legal é um poder arbitrário.
\end{abstract}

Portanto, observa se um ato pode ser legal (exemplo acima), isto é, conforme aos dispositivos legais, ser legítimo, vale dizer, estar de acordo com os valores fundamentais da sociedade, mas ser praticado ineficientemente, ante economicamente, o que significa dizer, com desperdício ou ainda com gastos superiores aos necessários à realização do ato.

\footnotetext{
${ }^{25}$ BASTOS, Celso Ribeiro. Curso de Direito Financeiro e Tributário. 9. ed. São Paulo: Celso Bastos Editor, 2002.

${ }^{26}$ ALEXANDRINO, Marcelo; PAULO, Vicente. Direito Administrativo. 12. ed. Rio de Janeiro: Impetus, 2006.

${ }^{27}$ BOBBIO, Norberto. Dicionário de política. 11. ed. vol. 2. Brasília: Editora Universidade de Brasília, 1998, p. 674.
} 
Por fim, por legalidade entende-se a conformidade do ato com a norma que o rege; por legitimidade entende-se a conformidade do ato com a moral administrativa e com o interesse coletivo (princípios da moralidade e da finalidade), indissociáveis de toda atividade pública.

\subsection{CONTROLE SOCIAL OU POPULAR}

Ensina-nos Medeiros (2016, p. 150) ${ }^{28}$ que toda a teoria política de Rousseau apoia-se na participação individual de cada cidadão no processo de tomada de decisões, e, em sua teoria, a participação é bem mais do que um complemento protetor de uma série de arranjos institucionais: ela também provoca um efeito psicológico sobre os que participam, assegurando uma interrelação contínua entre funcionamento das instituições e as qualidades e atitudes psicológicas dos indivíduos que interagem dentro delas.

Isto nos faz crer, que uma política baseada na participação direta dos cidadãos tornaria as decisões tomadas mais legítima perante todos, ganhando legitimidade e acima de tudo o controle dos atos efetivados pelos gestores públicos.

É possível afirmar que com o controle social haverá um incremento na disponibilização de informações exigidas por lei e facilitará a efetivação das políticas públicas de transparência.

Medida extremamente importante foi autorizada pelo legislador constitucional no art. 74, $\S 2^{\circ}$, que torna acessível ao povo a possibilidade de denunciar irregularidades ou ilegalidades perante o Tribunal de Contas da União ${ }^{29}$.

Assim, qualquer cidadão, partido político, associação ou sindicato é parte legítima para, na forma da lei, proceder a essas denúncias. Trata-se, de mais um instrumento colocado no arsenal dos direitos políticos do cidadão. Conforme o tipo de medida a ser impugnada, pode tornar-se mais conveniente e mais prático a simples denúncia ao Tribunal de Contas, que, no exercício de suas atribuições, poderá introduzir as impugnações e sanções que a hipótese comportar, evitando-se, destarte, o caminho mais complexo de uma Ação Popular. A expressão, na forma da lei, não deve induzir a ninguém a ideia de que o preceito por ora é inócuo, já que a referida lei não se encontra ainda editada.

\footnotetext{
${ }^{28}$ MEDEIROS, Pedro. Uma Introdução à Teoria da Democracia. Curitiba: Intersaberes, 2016, pág. 150.

${ }^{29}$ Art. $74(\ldots)$

$\S 2^{\circ}$ Qualquer cidadão, partido político, associação ou sindicato é parte legítima para, na forma da lei, denunciar irregularidades ou ilegalidades perante o Tribunal de Contas da União.
} 
A participação popular no controle da legalidade e moralidade da atividade administrativa pode, assim, ser exercida mediante Representação ${ }^{30}$, perante a própria Administração ou órgão do Ministério Público que tiver competência para apurar a prática da irregularidade ou ilegalidade apontada mediante Denúncia ${ }^{31}$ perante a Assembleia Legislativa ou Tribunal de Contas, como tmbém, mediante propositura da Ação Popular.

\title{
3. CONSIDERAÇÕES FINAIS
}

Conclui-se que os Tribunais de Contas, no ordenamento jurídico brasileiro, são órgãos independentes e autônomos, constitucionalmente instituídos, exercentes do controle externo, desvinculados de qualquer relação de subordinação com os Poderes, prestando auxílio de natureza técnica especializada ao Poder Legislativo, em que suas decisões não gozam de definitividade jurisdicional.

O legislador constituinte, também, com objetivo de melhor fiscalizar a aplicação dos recursos públicos, estabeleceu o controle interno realizado pela entidade ou órgão responsável pela atividade controlada, no âmbito da própria Administração e o controle social, onde qualquer cidadão, partido político, associação ou sindicato é parte legítima para, na forma da lei, proceder à apresentação de denúncias junto aos tribunais de contas. Trata-se, de novos instrumentos colocados no arsenal dos direitos políticos do cidadão.

\section{CONSTITUTIONAL-POLITICAL FOUNDATION FOR EXTERNAL CONTROL}

\begin{abstract}
This article aims to highlight the role played by the Court of Accounts in the Brazilian state from the Charter of 1988, in the attribution of exercising external control and accounting, financial, budgetary, operational and patrimonial oversight; point out irregularities and propose appropriate methods of applying public revenue. The internal control exercised by the Ministry of Transparency and Controllership of the Union, social control, parliamentary control and judicial or judicial control was also merited. We chose a study that was based on a qualitative research strategy. Oriented in a bibliographical research, consigned in contemporary works, in the great majority, of national authors. In addition, an analysis of current legislation, considering the
\end{abstract}

\footnotetext{
${ }^{30}$ Para CHAVES (2007), a Representação é um tipo de denúncia feita por pessoa ou entidade qualificada, servidores públicos (funcionários e empregados públicos, procuradores, entre outros) ou agentes políticos (senadores, deputados, juízes) que tenham tomado conhecimento de ocorrência irregular em função do cargo que ocupam e outras entidades públicas (câmaras municipais, ministérios públicos estaduais e outros tribunais de contas).

${ }^{31}$ As denúncias são processos pelos quais o Tribunal apura irregularidades informadas por cidadãos ou pessoa jurídica da sociedade civil (sindicato, associação ou partido político). Esse procedimento é apurado em caráter sigiloso até que, confirmada a sua procedência, o Tribunal torne o público.
} 
historical context, which represents some of the regulatory frameworks of public administration control in Brazil.

Keywords: Internal Control. External Control. Social Control. Administrative Control.

\section{REFERÊNCIAS}

ALEXANDRINO, Marcelo; PAULO, Vicente. Direito Administrativo. 12. ed. Rio de Janeiro: Impetus, 2006.

AUlete, Caldas. Dicionário Contemporâneo da Língua Portuguesa, Rio de Janeiro, Editora

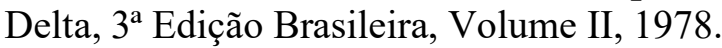

BASTOS, Celso Ribeiro. Curso de Direito Financeiro e Tributário. 9. ed. São Paulo: Celso Bastos Editor, 2002.

BOBBIO, Norberto. Dicionário de política. 11. ed. vol. 2. Brasília: Editora Universidade de Brasília, 1998, p. 674.

CASTRO, Celso Antônio Pinheiro de. Ciência Política: Uma Introdução. São Paulo: Atlas, 2004.

CHAVES, Francisco Eduardo Carrilho. Controle Externo da Gestão Pública. Niterói: Impetus, 2007.

FERREIRA, Aurélio Buarque de Holanda. Novo Dicionário da Língua Portuguesa. Rio de Janeiro, Editora Nova Fronteira, $2^{\text {a }}$ edição revista e aumentada, 1986.

JARDIM, Eduardo Marcial Ferreira. Manual de Direito Financeiro e Tributário. 8. ed. São Paulo: Saraiva, 2007.

MARIN, Jeferson Dytz; BERTARELLO, Marina. Democracia e políticas públicas: uma leitura a partir dos direitos humanos. Revista de Estudos Constitucionais, Hermenêutica e Teoria do Direito (RECHTD) 4(1): 57-64 janeiro-junho 2012.

MEDEIROS, Pedro. Uma Introdução à Teoria da Democracia. Curitiba: InterSaberes, 2016.

MEIRELLES, Hely Lopes. Direito Administrativo Brasileiro. 22. ed. São Paulo: Malheiros, 1997.

OLIVEIRA, Cláudio Brandão de. Manual de Direito Administrativo. 3. ed. Rio de Janeiro: Impetus, 2006.

OLIVEIRA, Regis Fernandes de. HORVATH, Estevão. Manual de Direito Financeiro. 6. ed. São Paulo: Editora Revista dos Tribunais, 2003.

PESSANHA, Charles. Controle Externo: a função esquecida do legislativo no Brasil. Disponível em http://www.schwartzman.org.br/simon/fest12_charles.pdf, acessado em: 14 out. 2018. 
PESSANHA, Charles. O Tribunal de Contas, o Congresso Nacional e as Contas Presidenciais. Disponível em http://www.congresoalacip2017.org/arquivo/downloadpublic2?q=YToyOntzOjY6InBhcmFtcyI 7czozNToiYToxOntzOjEwOiJJRF9BUIFVSVZPIjtzOjQ6IjI5NjUiO30iO3M6MToiaCI7czoz MjoiMTk1MzNhNTBlYWM0MDZjZGJiNjk3ZTJjYTY0MmY3Y2UiO30\%3D, Acessado em 16 de Out. 2018.

ROCHA, C. Alexandre Amorim. O Modelo de Controle Externo Exercido pelos Tribunais de Contas $e$ as Proposições Legislativas sobre o Tema. Disponível em: $<$ http://www.planalto.gov.br/CCIVIL/Consulta_Publica/agencia_nacion.htm>. Acessado em: 04 jun.2018.

Trabalho enviado em 31 de março de 2019 Aceito em 01 de maio de 2020 